Int. J. Electrochem. Sci., 11 (2016) $4930-4942$

\title{
Comparative Investigation of $\beta$ - and $\gamma$-cyclodextrin as Ionophores in Potentiometric Based Sensors for Naltrexone
}

\author{
H. AlRabiah ${ }^{1}$, M.A. Abounassif ${ }^{1}$, A. Al-Majed ${ }^{1}$, G. A.E. Mostafa ${ }^{1,2, *}$ \\ ${ }^{1}$ Pharmaceutical Chemistry Department, College of Pharmacy, King Saud University, P.O.Box 2457, \\ Riyadh11451, Saudi Arabia. \\ ${ }^{2}$ Micro-analytical Lab., Applied organic Chemistry Department, National Research Center, Dokki, \\ Cairo, Egypt. *E-mail: gamal_most@yahoo.com
}

doi: $10.20964 / 2016.06 .10$

Received: 23 February 2016 / Accepted: 6 April 2016 / Published: 4 May 2016

\begin{abstract}
The formation and developed of Polyvinyl chloride (PVC) membrane sensors for naltrexone (NALT) are examined. The electroactive elements contains molecular recognition components $\beta$ - or $\gamma$ cyclodextrin as ionophores. Sensor 1 was fabricated using $\beta$ - cyclodextrin, while sensor 2 was used $\gamma$ cyclodextrin in presence of potassium tetrakis (4-chlorophenyl)borate as ion additive, PVC as matrix and dioctylphthalate as plasticizer. The sensors show rapid, fixed and sub-Nernstian response (38 and $34 \mathrm{~m} /$ decade) meantime a relative wide naltrexone dynamic range $\left(1 \times 10^{-2}-5.8 \times 10^{-6}\right.$ and $1 \times 10^{-2}-$ $4.0 \times 10^{-6} \mathrm{M}$ ), with detection limits of $5 \times 10^{-6}$, and $3.0 \times 10^{-6} \mathrm{M}$ for $\beta$ - or $\gamma$ - cyclodextrin sensor, respectively. The optimum $\mathrm{pH}$ was in range of $2.0-7.0$. The investigated sensors show a good selectivity for NALT with respect of different ions. The determination of $300 \mu \mathrm{g} / \mathrm{ml}$ of naltrexone appear a recovery value of $97.2 \%$ and $97.5 \%$, respectively with mean RSD values of $1.7 \%$ and $2.0 \%$ for sensors 1 and 2 . The examined sensors have been used for the assay of NALT in its dosage form. The outcome data for the assay of naltrexone in tablet using the investigated sensors are good convention with the published spectrophotometric procedure. Potentiometric titrations of naltrexone using the examined sensors have been carried out.
\end{abstract}

Keywords: Naltrexone $\mathrm{HCl}, \quad \beta$ - and $\gamma$-cyclodextrin, PVC, Potentiometry.

\section{$\underline{\text { FULL TEXT }}$}

(C) 2016 The Authors. Published by ESG (www.electrochemsci.org). This article is an open access article distributed under the terms and conditions of the Creative Commons Attribution license (http://creativecommons.org/licenses/by/4.0/). 